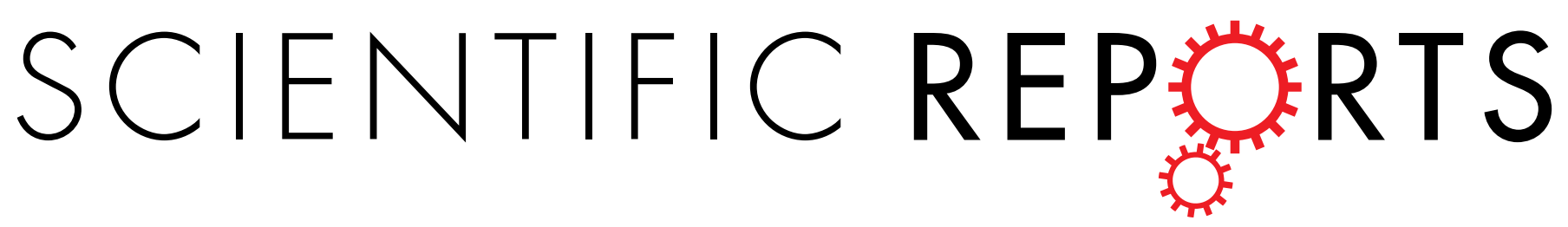

\title{
OPEN
}

\section{vesicoureteric reflux}

\author{
John M. Darlow ${ }^{1,2}$, Rebecca Darlay ${ }^{3}$, Mark G. Dobson ${ }^{1,2}$, Aisling Stewart ${ }^{3}$, Pimphen \\ Charoen $^{4,5}$, Jennifer Southgate $\mathbb{1}^{6}{ }^{6}$, Simon C. Baker $\mathbb{D}^{6}$, Yaobo $\mathrm{Xu}^{3}$, Manuela Hunziker ${ }^{2,7}$, \\ Heather J. Lambert ${ }^{8}$, Andrew J. Green ${ }^{1,9}$, Mauro Santibanez-Koref ${ }^{3}$, John A. Sayer $\mathbb{1}^{3}$, \\ Timothy H. J. Goodship ${ }^{3}$, Prem Puri²,10, Adrian S. Woolf $\mathbb{D}^{11,12}$, Rajko B. Kenda ${ }^{13}$, David E. \\ Barton $^{1,9}$ \& Heather J. Cordell ${ }^{3}$
}

Correction to: Scientific Reports https://doi.org/10.1038/s41598-017-15062-9, published online 03 November 2017

The original HTML version of this Article contained a typographical error in the publication date ' 03 November 2017' which was incorrectly given as '06 November 2017'. This has now been corrected in the HTML version of the Article.

(i) Open Access This article is licensed under a Creative Commons Attribution 4.0 International License, which permits use, sharing, adaptation, distribution and reproduction in any medium or format, as long as you give appropriate credit to the original author(s) and the source, provide a link to the Creative Commons license, and indicate if changes were made. The images or other third party material in this article are included in the article's Creative Commons license, unless indicated otherwise in a credit line to the material. If material is not included in the article's Creative Commons license and your intended use is not permitted by statutory regulation or exceeds the permitted use, you will need to obtain permission directly from the copyright holder. To view a copy of this license, visit http://creativecommons.org/licenses/by/4.0/.

(C) The Author(s) 2017

\footnotetext{
${ }^{1}$ Department of Clinical Genetics, Our Lady's Children's Hospital, Crumlin, Dublin 12, Ireland. ${ }^{2 N a t i o n a l ~ C h i l d r e n ' s ~}$ Research Centre, Our Lady's Children's Hospital, Crumlin, Dublin 12, Ireland. Institute of Genetic Medicine, Newcastle University, Central Parkway, Newcastle upon Tyne, NE1 3BZ, UK. ${ }^{4}$ UCL Institute of Health Informatics, University College, London, NW1 2DA, UK. ${ }^{5}$ Department of Tropical Hygiene, Faculty of Tropical Medicine, Mahidol University, Bangkok, 10400, Thailand. ${ }^{6} J a c k$ Birch Unit of Molecular Carcinogenesis, Department of Biology, University of York, York, YO10 5DD, UK. 'University Children's Hospital Zurich, Steinwiesstrasse 75, 8032, Zurich, Switzerland. ${ }^{8}$ Royal Victoria Infirmary, Newcastle upon Tyne, NE1 4LP, UK. ${ }^{9}$ University College Dublin School of Medicine, Our Lady's Children's Hospital, Crumlin, Dublin 12, Ireland. ${ }^{10}$ University College Dublin, Stillorgan Rd, Belfield, Dublin 4, Ireland. ${ }^{11}$ Division of Cell Matrix Biology and Regenerative Medicine, Faculty of Biology, Medicine and Health, University of Manchester, Manchester, UK. ${ }^{12}$ Royal Manchester Children's Hospital and Manchester Academic Health Sciences Centre, Manchester, UK. ${ }^{13}$ Department of Pediatric Nephrology, University Medical Centre Ljubljana, Ljubljana, Slovenia. John M. Darlow and Rebecca Darlay contributed equally to this work. Correspondence and requests for materials should be addressed to H.J.C. (email: heather.cordell@newcastle.ac.uk)
} 